\title{
Research on the Interactive Teaching Mode and Quality-Oriented Education Theory with Its Applications on Colleges and Universities Sports Teaching
}

\author{
Jiangjing Du \\ Institute of Physical and Health Education of Mianyang Normal University, \\ Mianyang,Sichuan,China
}

\begin{abstract}
In this paper, we conduct research on the interactive teaching mode and the quality-oriented education theory with its applications on colleges and universities sports teaching. Physical education class hours are limited. In the teaching material content on the choice of considering the students' ability of sports in the feasibility and practicability of lifelong exercise and in addition, the rational knowledge of college students and autonomous ability is stronger to theoretically enlightening and the guiding them to make them realize the importance of lifelong physical exercise and how to make the scientific exercise, at the same time, students interested in courses in practice. Fully mobilize and motivate them to exercise initiative and self-consciousness. In summary, our methodology provides the novel perspective of the reform which holds special significance.
\end{abstract}

Keywords- Interactive Teaching, Quality-Oriented, Education Theory, Sports Teaching, College.

\section{Introduction}

University-based curriculum implementation is in accord with national and local school curriculum standard, according to the resource conditions and the actual situation of the students of the school for some in school-based curriculum construction and improvement activities which it is a continuous, dynamic, gradually perfect process. Any kind of the curriculum implementation needs to verify their effectiveness through evaluation, through evaluation, feedback and coordination and communication to seek more conducive to the way of curriculum implementation. Also, university-based curriculum implementation needs developing and perfecting through evaluation [1-3].

Theoretically speaking, the general levels of the physical training could be summarized as follows. (1) Basic quality. The fundamental, the students' physical quality is one of the students training sports schools must have one of the most basic quality, is proposed to satisfy the demand of the social sports teaching the most basic requirements. It includes the student good volition and character of the strong physique and two aspects. (2) Innovation quality. Quality education should be essentially innovation education. Students only starting from the basic quality and the development to have the innovation quality, able to independently carry out the creative work, the goals of quality education will be truly implemented. For the sports quality education that is to make students have a reasonable knowledge structure, sports intelligence and general intelligence. Knowledge structure is the foundation of the students engaged in creative work, it is not the same as knowledge or knowledge of, and should be based on the knowledge inner link of freely crisscross of organized knowledge. (3) The development of quality. Development of quality refers to the movement ability of students and non-intelligence factors. They are formed on the primary basis of the basic qualities, but it is also the foundation of the innovation quality to have a strong physique is not equal to have the sports ability at the same time.

Sports teaching reform advocating the sports education workers to meet the needs of the 
people themselves, education and social, through inspiration and guide the educatee inner demand, creating a series of harmonious, democratic, loose environment, purposeful, planned and organized to teaching, and make them become the study master, increase their autonomy and creativity. In the process of teaching is only the teacher's leading role and students' main body role both harmony and unity as will reach the real teaching purpose and effect. Interaction between teachers and students as refers to the process of interaction and mutual influence between teachers and students. The interaction between teachers and students in the classroom is refers to between teachers and the students in the teaching situation of the interaction has a promoting or inhibiting or influence [4].

Teachers should focus on students, to guide students in class, students pay attention to the teacher in class rely on the teachers in their own way at the same time affecting the teachers. The time of the dialogue between teachers and students is an important index for measuring interaction conditions, teachers and students consistent aim, to complete the common task of the teaching can work together, mutual dependence to take the initiative to coordinate each other, take strategy, efforts to achieve the goal, the benign interaction between the teachers and students as shown in the figure one.

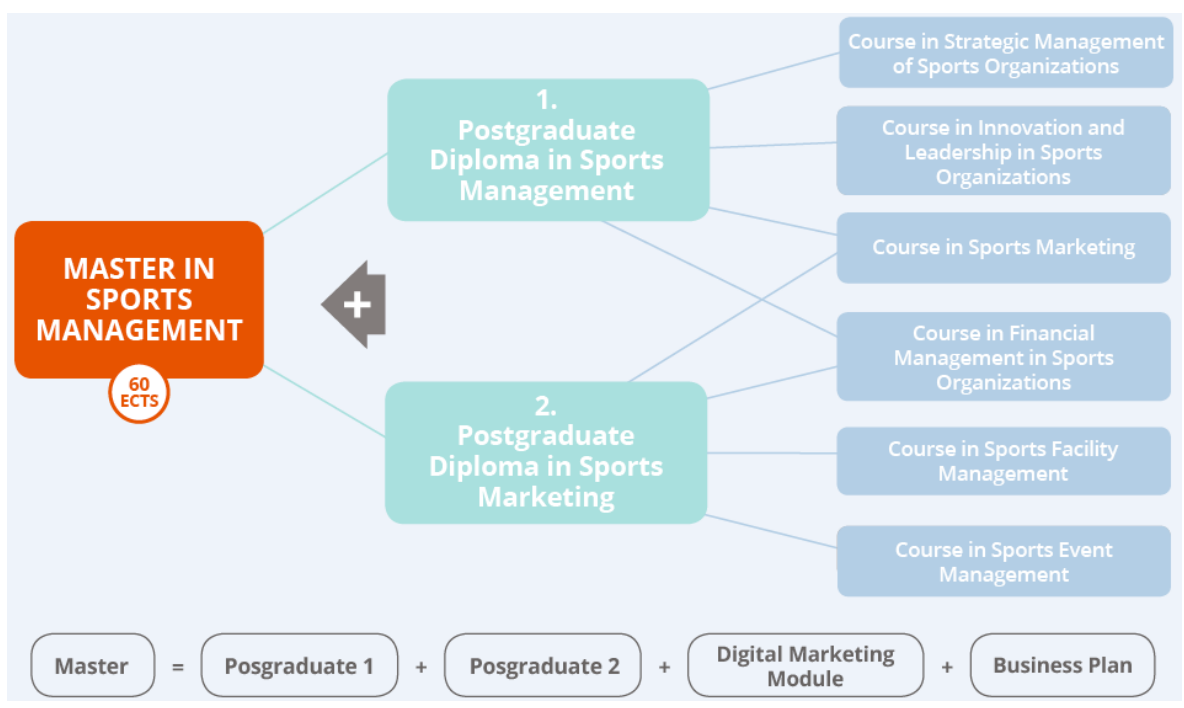

Figure 1. The Systematic Architecture of the Interactive Teaching Mode

In this paper, we conduct research on interactive teaching mode and the quality-oriented education theory with its applications on colleges and the universities sports teaching. In the sports teaching to strengthen the physical exercise need knowledge imparting scientific knowledge and the human body, including the sports effect on the human body, principle and method of the physical training, physical health, mental health and physical measurement and evaluation of knowledge. Therefore, colleges and universities sports teaching and strengthen the sports teaching of the theoretical knowledge. It is an effective way of training students' physical training habits. In the following sections, we will get more in-depth analysis on the corresponding modifications.

\section{Our Proposed Methodology}

The Physical Education Teaching Reform. With highly diversified, science and technology of the advent of the era of knowledge economy, the international competition is the essence of the based on economic and technological strength of the comprehensive national strength, the 
development of the science and technology must rely on education and cultivate talents. Education related to the talents cultivation of modern construction in our country, and sports the significant role in the process of the education development in our country. Sports is the talent development of health care in an all-round way, thus we should not only pay attention to the quality of physical education teaching and the effect on training students in the process of teaching, but also to pay attention to in the process of sports teaching to cultivate students life-long physical exercise ideas and learn skills and methods. Based on the literature review, the reform of physical education should follow the listed guidelines [5].

- Work out teaching plans and goals. After the implementation of the sports educational reform, many schools because of the basic influence of the exam-oriented education, to other entrance instead of the physical education curriculum, the curriculum to the normal there is no way to carry out physical education curriculum. In view of the above situation, the school must adopt corresponding countermeasures, to work out teaching plans and goals, so that basic physical education curriculum carried out smoothly.

- Create a good classroom atmosphere. Changing teaching content, teaching content of and practical life have a connection that cause the student's curiosity, and then to make the students on the course for the sports interest, if the students can be interested in the physical education curriculum, will make the original classroom atmosphere to obtain very good improvement, and raise the achievement of the students' sports.

- Comprehensive evaluation assessment system. Sports theory including the basic knowledge of the professional sports, current events, sports, sports meet, etc., sports practice includes skills application ability, learning attitude, affective inputs, improve the extent of morning exercises and the number of extracurricular activities. Sports training, sports competition, after-school sports activities, such as basic physical health test including height, weight, bench test, vital capacity, etc. according to the weight of each assessment project proportion coefficient. Adopt the method of comprehensive evaluation assessment [6].

- Practice teaching, face-to-face class inside and the outside integration. Give full play to the function of physical education in college education system and the function. Inside, internal and external integration of the teaching, more effectively improve students' physical fitness. Improve the health status of the students to promote the students comprehensive development.

The Quality-Oriented Teaching Pattern. Quality education is the all-round development of the people's general ideological and moral qualities, cultural science quality, labor skills quality and the psychological quality as the primary goal of the education. Quality education is our country education development direction and the basic requirements, sports as an important aspect of education in the quality education has a very significant position and important role. Quality education is put forward in view of the shortcomings of exam-oriented education. It contains the new education idea to China's education has brought a strong impact and thus triggered a huge education reforms. Quality education is not only simple in view of the test, it is not meant to abolish the examination system, but in view of the traditional education caused by backward education idea of the one-sided development of human beings and out of the practical need of society from the people. 
Physical quality and overall quality is inseparable relationship. In the development of the overall quality, the sports quality is only a part of the quality education, its role is to improve and promote the development of quality education. Both influence each other, promote each other. Physical education is a special education curriculum with it is significant, since the childhood, it is an effective way of the training students' physical and mental health is an important means of training students will. The basic functionality of the training could be generally summarized as the follows. (1) Cultivate the students' competitive consciousness and enterprising spirit. Activists have to achieve the goal of psychological motivation as soon as possible. Therefore, for the school sports must be geared to the needs of all students, for the aim of school physical education, content and methods of the selection, examination standards and have to take care of all the students of physical education learning practice. (2) Promote the development of students' intelligence. Sports can promote the development of the brain, the brain central nervous system to improve its function, for the people engaged in mental activity to lay a good foundation. (3) Cultivating students' healthy aesthetic idea and aesthetic ability as students not only to form beauty, beauty of mind. Sports is one of the important means of general implementing aesthetic education, in a variety of school sports, the use of all kinds of teaching means, teachers all sorts of the queue practice and technology practice, all kinds of sports competition and performance, and sports equipment layout, etc. that can make the students influenced by the physical beauty and inner beauty.

The Interactive Teaching Mode. We usually lectures the main drawback is that in essence it is a unidirectional thinking way of primary communication, mainly teachers' explanation, demonstration, requirements, so it is easy to make students tired, excitement sharply reduce, even sleep. So successful language teaching is it must be attractive and must be vividly interactivity. With vivid interactive, can promote students high spirits, active thinking that make the students make the self-awareness, and the actively participate in practice with the better to master what they have learned.

Constructivism puts forward subjectivity of knowledge. Belief in the understanding of knowledge is a kind of interpretation of the objective world and assumptions and no real perfect interpretation. Just with the deepening of human understanding and make a new interpretation and assumptions [7].

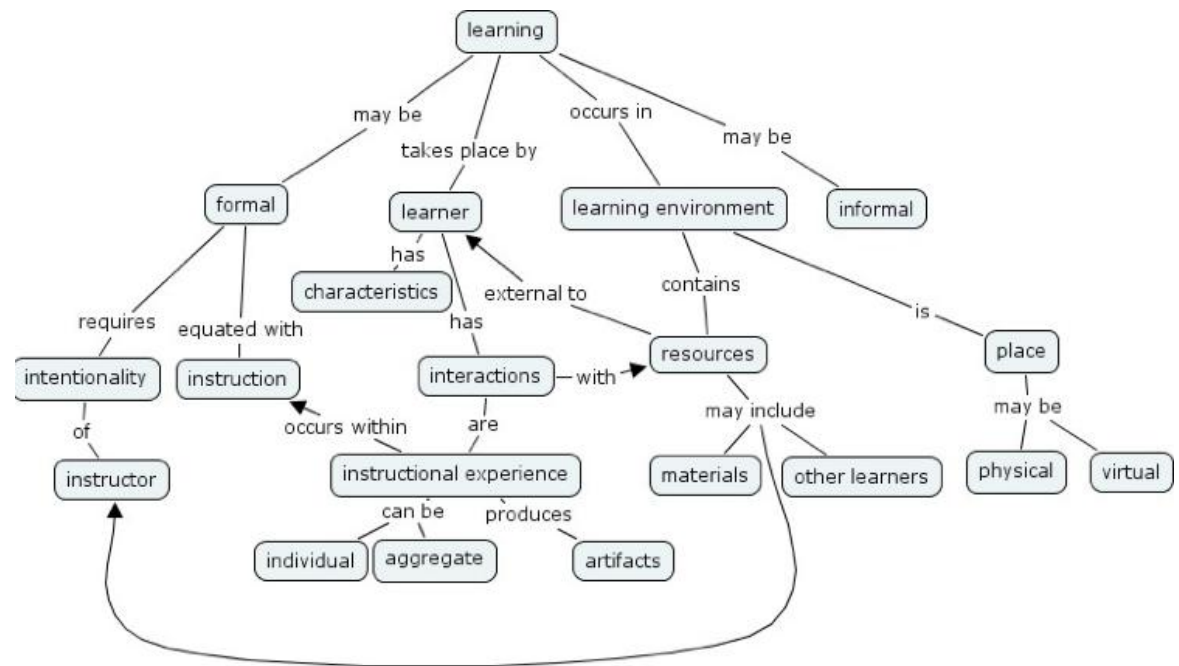

Figure 2. The Architecture of the Interactive Teaching Methodology 
In the sports teaching of interpersonal information communication system, although the student basically is the recipient of the information, but this is not a passive, but an active cognitive process. Teachers passed by all kinds of information can be accepted by students effectively, depends on the student's independent active state. These state independent activities including the sports knowledge, skills, abilities, students have mastered existing physical quality level, learning interest and attitude, and the consciousness of the learning motivation, etc. At the same time, the interpersonal information communication in the sports teaching, the students will produce certain attitude of teachers, and basic student attitude towards teachers also directly affects the student to accept the effect of information.

The Future of the PE Education. Build system of the college PE evaluation, in order to review construction, to build and promote general development. Functions of the education of colleges and universities should set up college $\mathrm{PE}$ evaluation system to promote the construction and development of college sports. In the process of establishing college PE evaluation system to build a scientific evaluation system, a reasonable solution to evaluate the frequency, the authenticity of the assessment, the results of the assessment system of the social public problems. Only set up scientific evaluation system can reflect the reality of the college sports, provide reliable materials for the reform of college sports development. The updating procedure should cover the listed aspects. (1) The teaching content reform must be adapted to the basic teaching goal. Choose the teaching content, should attach great importance to the value of its biological transformation to the human body, and to consider it for the role of sports culture and education. According to the characteristics of students, who can effectively develop students' physical quality, basic activities to improve student ability that is beneficial to carry forward national traditional sports culture in our country, stimulate student competitive consciousness and meet their interest in sport as the content of the textbook. (2) To strengthen the health education content. School sports must exercise combined with maintenance of the road, to strengthen the health education of students. When choosing the teaching material content, increase the students willing to attend, for sports students' physical and mental health. (3) Teaching content should be suitable to the content of sports and lifelong exercise. The direction of the university sports education is a lifelong sports to make the students out of school after, still can insist to take exercise, benefit for life and the education of PE of universities and colleges over the past, in large part, not the principles and methods for the exercise system thoroughly to teach students [8].

\section{Conclusion}

In this paper, we conduct research on the interactive teaching mode and the quality-oriented education theory with its applications on colleges and universities sports teaching. With the further development of the national education system reform, higher vocational education is more prominent in the field of the education. To adapt to the professional structure and the change of industrial structure, make the employment act in line with international standards. Promote the development of social economy and so on of the role of more and more important. The higher vocational colleges and universities sports education appears more important. Under the background of the new situation, the reform of higher vocational physical education curriculum should actively use seek. In order to meet the needs of the development of times, this article first analysis of the contemporary sports curriculum educational reform goals. Then put forward a set of implementation way, hope has enlightening significance to peers. Through using the principles of the interactive teaching mode and quality-oriented education theory, our 
suggestion could achieve better realistic performance.

\section{References}

[1] Yuan, Z. H. A. O., Z. H. Ni, and G. U. O. Ge. "Interactive Teaching of the Lorentz Force in Medical Physics." Chinese Journal of Medical Physics 1 (2013): 033.

[2] Peng, X. I. "Application of Interactive and Opening Teaching Mode in Polymer Chemistry Teaching [J]." Polymer Bulletin 6 (2012): 018.

[3] Li, Lie-Ming, Bin Li, and Ying Luo. "Using a dual safeguard web-based interactive teaching approach in an introductory physics class." Physical Review Special Topics-Physics Education Research 11.1 (2015): 010106.

[4] Chumbo, Isabel, and Elisabete Mendes Silva, eds. "Interactive Teaching Across Culture and Technology." (2015).
[5] Huijie, J. I. A. N. G., et al. "Application of PACS-based net interactive teaching in medical imaging." Basic Medical Education 8 (2013): 024.

[6] Färnqvist, Tommy, et al. "Supporting Active Learning by Introducing an Interactive Teaching Tool in a Data Structures and Algorithms." 47th ACM Technical Symposium on Computer Science Education (SIGCSE 2016), Memphis, Tennessee, USA, March 2-5, 2016. 2016.

[7] Schmitt, Lothar M. "A Decentralised Approach to Computer Aided Teaching via Interactive Documents." Databases in Networked Information Systems. Springer International Publishing, 2015. 277-288.

[8] Potter, C., and G. Naidoo. "Enhancing classroom teaching through Interactive Radio in South African primary schools: An evaluation of the OLSET programme." Africa Education Review 9.3 (2012): 518-547. 